\title{
Vancomycin-induced drug rash with eosinophilia and systemic symptoms (DRESS)
}

\author{
Kyle Yuan (1) , 1,2 Kanwal S Awan, ${ }^{1}$ James Long ${ }^{1}$
}

'Department of Internal Medicine, Walter Reed National Military Medical Center, Bethesda, Maryland, USA ${ }^{2}$ Uniformed Services University of the Health Sciences, Bethesda, Maryland, USA

\section{Correspondence to} Dr Kanwal S Awan; kanwal.s.awan.civ@mail.mil

Accepted 5 November 2019

\section{DESCRIPTION}

A 52-year-old previously healthy man presented to the emergency department with pruritic rash, angioedema and fever of $39.3^{\circ} \mathrm{C}$ that started the day previously. Four weeks ago, he was treated for left fifth digit osteomyelitis with surgical debridement and initiated a 6-week course of vancomycin and ertapenem. Skin examination was notable for diffuse erythematous folliculocentric papules that initially appeared on his neck and spread down his torso to bilateral upper and lower extremities (figure 1). The next day, his rash continued to spread to bilateral palms and soles. The patient promptly halted antibiotics and was admitted to the intensive care unit due to significant facial swelling causing concern for impending airway compromise. Laboratory findings showed eosinophilia with 2026 eosinophils per microlitre (reference range, 50-350), elevated serum IgE of 151.9 units per millilitre (reference range, $<100$ ), atypical lymphocytes and acute kidney injury. Of note, this patient's aspartate aminotransferase (reference range, 0-40) and alanine aminotransferase (reference range, 0-41) remained within normal limits throughout his entire hospitalisation. There was no palpable lymphadenopathy. Blood cultures, antinuclear

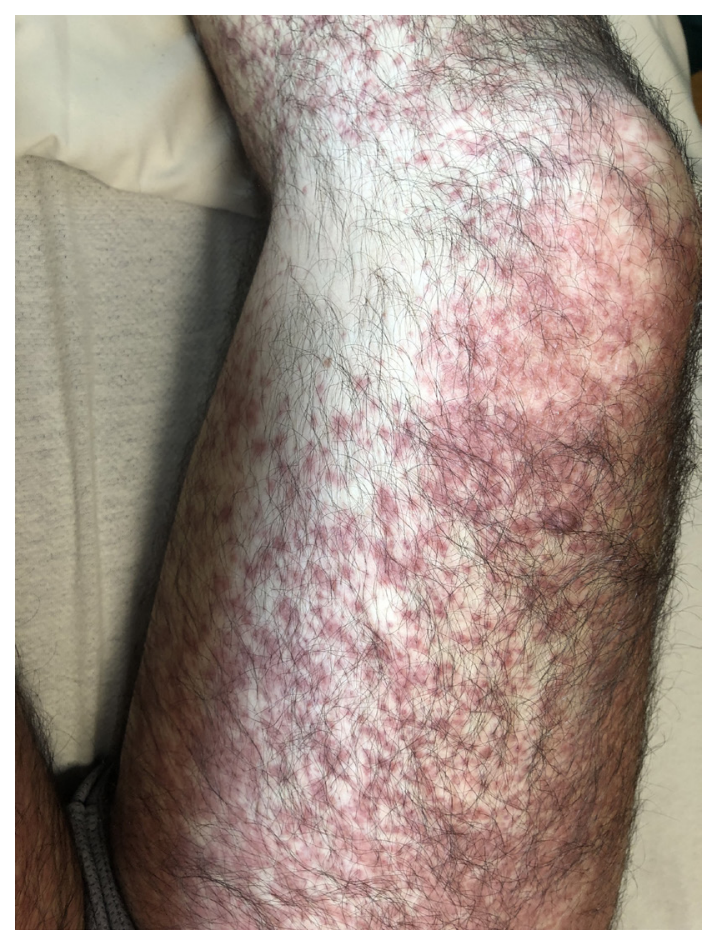

Figure 1 Diffuse erythematous morbilliform rash covering the patient's bilateral lower extremities.

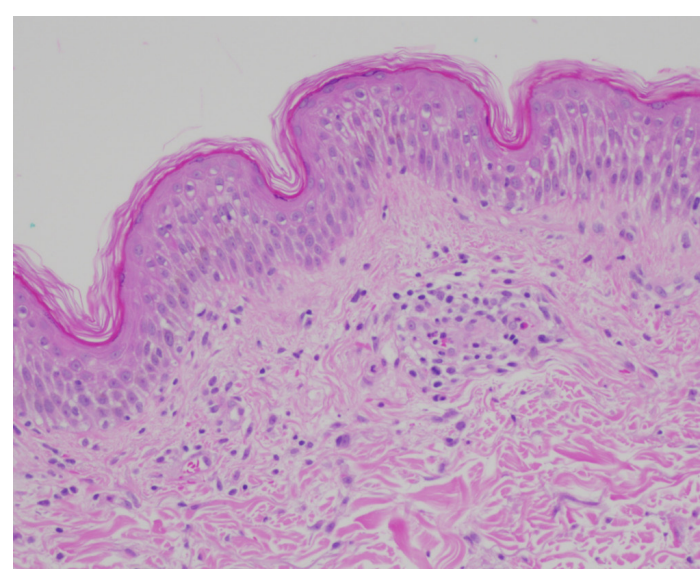

Figure 2 Skin biopsy showing spongiotic dermatitis with perivascular eosinophils.

antibody, HIV, HSV and hepatitis serologies were negative. Skin biopsy revealed spongiotic dermatitis with notable perivascular eosinophils (figure 2). The patient was diagnosed with drug rash with eosinophilia and systemic symptoms (DRESS) syndrome secondary to vancomycin. He had eight points on the scoring system developed by the European Registry of Severe Cutaneous Adverse Reactions, indicating a very high likelihood of DRESS syndrome. The patient was treated with 3 days of intravenous methylprednisolone which improved his facial swelling and rash. He was then discharged to complete a 6-week oral prednisone taper with complete resolution of DRESS.

DRESS syndrome is a rare but potentially lethal drug-induced hypersensitivity leading to multisystem compromise. Vancomycin is an uncommon cause of DRESS syndrome, but some patients may be genetically predisposed due to human leukocyte antigen (HLA) variations. ${ }^{1}$ Vancomycin-induced DRESS tends to present with greater incidence of renal impairment compared with other drugs. ${ }^{2}$ Hepatic compromise from vancomycin-induced DRESS can be variable, with some patients presenting with significant transaminitis. ${ }^{3-5}$ Other patients may present with only a mild elevation in liver function tests; these patients tend to be younger and healthier, like the one presented in this report. ${ }^{67}$ Previously published cases of vancomycininduced DRESS report onset of symptoms after at least 3 weeks of antibiotic therapy. ${ }^{3-7}$ This suggests that patients who require greater duration of vancomycin therapy, such as those with endocarditis or osteomyelitis, are at greater risk of developing DRESS. 


\section{Patient's perspective}

After discharge, my rash and facial swelling began to steadily improve, resolving within two weeks. I followed up with dermatology, allergy, orthopaedics and internal medicine afterwards. With respect to the osteomyelitis, during my admission my antibiotics were switched to IV daptomycin and moxifloxacin. I completed these medications for two more weeks to complete the originally planned six-week course of antibiotics. By then, the degree of swelling and pain in my pinkie had improved significantly so I started physical therapy which is helping me regain my baseline level of function. It has been a pleasure working with the physicians here and I am especially grateful that we did not have to amputate the finger.

\section{Learning points}

Drug rash with eosinophilia and systemic symptoms (DRESS) syndrome should be suspected in any patient with diffuse morbilliform rash covering greater than $50 \%$ of body surface area, especially 2-6weeks after starting the offending medication.

- Although vancomycin is an uncommon cause of DRESS syndrome, patients who require prolonged ( $>3$ weeks) vancomycin therapy may be at greater risk.

- DRESS syndrome can be diagnosed with European Registry of Severe Cutaneous Adverse Reactions criteria, which takes into account fever, eosinophilia, lymph node enlargement, atypical lymphocytes, organ involvement and rash characteristics.
Acknowledgements We would like to express our sincere gratitude for the patient. He was a pleasure to work with throughout the hospitalisation and during the development of this report.

Contributors KY, medical student, obtained the images and wrote the vignette for the report. KSA was the attending physician for this case. She also provided mentoring and editorial expertise. JL provided pathology images and descriptions.

Funding The authors have not declared a specific grant for this research from any funding agency in the public, commercial or not-for-profit sectors.

Competing interests None declared.

Patient consent for publication Obtained.

Provenance and peer review Not commissioned; externally peer reviewed.

\section{ORCID iD}

Kyle Yuan http://orcid.org/0000-0002-3248-1799

\section{REFERENCES}

1 Konvinse KC, Trubiano JA, Pavlos R, et al. HLA-A*32:01 is strongly associated with vancomycin-induced drug reaction with eosinophilia and systemic symptoms. J Allergy Clin Immunol 2019;144:183-92.

2 Madigan LM, Fox LP. Vancomycin-associated drug-induced hypersensitivity syndrome. J Am Acad Dermatol 2019;81:123-8.

3 Mennicke M, Zawodniak A, Keller M, et al. Fulminant liver failure after vancomycin in a sulfasalazine-induced DRESS syndrome: fatal recurrence after liver transplantation. Am J Transplant 2009;9:2197-202.

4 Gangireddy M, Sarao MS, Shrimanker I, et al. A fatal case of vancomycin associated drug reaction with eosinophilia and systemic symptoms syndrome in a Septuagenarian. Cureus 2019;11:e5015.

5 Roy S, Goswamy VP, Barssoum KN, et al. Vancomycin-Induced Drug Reaction with Eosinophilia and Systemic Symptoms (DRESS) syndrome masquerading as elusive sepsis. Case Reports Immunol 2019;2019:1625010:1-5.

6 Chamorro-Pareja N, Patel A, Youngberg G, et al. Case of drug reaction with eosinophilia and systemic symptoms secondary to vancomycin. BMJ Case Rep 2018;2018. doi:10.1136/bcr-2018-227378. [Epub ahead of print: 08 Oct 2018].

7 Maldonado D, Lakhani J. Vancomycin-induced DRESS syndrome treated with systemic steroids in a 16-year-old male. SAGE Open Med Case Rep 2019;7:2050313X19841704.

Copyright 2020 BMJ Publishing Group. All rights reserved. For permission to reuse any of this content visit

https://www.bmj.com/company/products-services/rights-and-licensing/permissions/

BMJ Case Report Fellows may re-use this article for personal use and teaching without any further permission.

Become a Fellow of BMJ Case Reports today and you can:

- Submit as many cases as you like

- Enjoy fast sympathetic peer review and rapid publication of accepted articles

- Access all the published articles

- Re-use any of the published material for personal use and teaching without further permission

Customer Service

If you have any further queries about your subscription, please contact our customer services team on +44 (0) 2071111105 or via email at support@bmj.com.

Visit casereports.bmj.com for more articles like this and to become a Fellow 